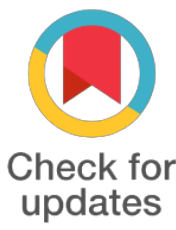

*For correspondence:

ngtnthanh@hcmus.edu.vn

Competing interests: The authors declare that no competing interests exist.

Received: 2017-05-28

Accepted: 2017-07-05

Published: 2017-09-05

Copyright The Author(s) 2017. This article is published with open access by BioMedPress (BMP).

This article is distributed under the terms of the Creative Commons Attribution License (CC-BY 4.0) which permits any use, distribution, and reproduction in any medium, provided the original author(s) and the source are credited.

\section{Rs3803662 significant associated with breast cancer risk in Vietnamese population}

\author{
Thanh Nguyen Thi-Ngoc, Phan Thanh Phat, Tran Bao Ngoc, Tran Van Thiep, and \\ Nguyen Thi Hue
}

Univeristy of Science, Vietnam National University, Ho Chi Minh City, Vietnam

\section{Abstract}

Breast cancer is one of the most common malignancies among women worldwide. GWASs have found several potential breast cancer associated SNPs in some populations. Among them, rs13281615, rs889312, rs10941679 and rs3803662 have been found to have strong relationship with breast cancer risk in different populations. Rs3803662 were statistiacally significantly associated with breast cancer risk in Asian population, while three others SNPs were showed to have stronger association with breast cancer in American, European and Australian than Asian. In this study, focusing on Vietnamese people only, four these SNPs were investigated to understand more about the association between these variations with breast cancer disease. An optimized genotyping method was used to genotype 600 samples including 300 controls and 300 cases. The result showed that rs13281615, rs889312, and rs10941679 were not associated with Vietnamese breast cancer patients $(P>0.05)$. However, $r 53803662$ has strong association with breast cancer risk in Vietnamese population $(P=0.00122, \mathrm{OR}=1.454,95 \% \mathrm{Cl}=1.159-1.826)$. Allele A plays the role of increasing the risk of breast cancer and the genotype AA shows strongly affecting to increase breast cancer risk. Rs3803662 may involve in the list of markers using for diagnosis breast cancer in Vietnamese people in the future. A further study on larger sample size is certainly required to increase the reliability of the study. We also suggest doing more association studies for other SNPs and analyzing the haplotype to identify multiple breast cancer risk prediction markers for Vietnamese population.

\section{Keywords}

Breast cancer, High Resolution Melting, SNP, rs13281615, rs889312, rs10941679, rs3803662, Vietnamese

Funding

Nafosted

\section{References}

